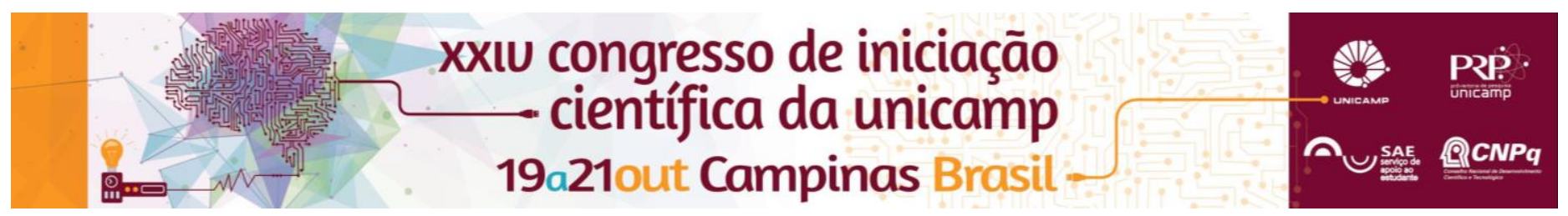

\title{
Aplicação de métodos computacionais na análise de tomografia computadorizada de amostras de rochas sedimentares.
}

\section{João Paulo da Ponte Souza}

\section{Resumo}

O objetivo desse trabalho é verificar a usabilidade de rotinas computacionais, como redes neurais, algoritmos genéticos, entre outros, na análise de amostras sedimentares através de imagens obtidas por Tomografia Computadorizada (TC), buscando aprimorar a precisão e dimiuir a diferença dos resultados comparado à análises realizadas em laboratórios.

\section{Palavras-chave: \\ Métodos computacionais, tomografia computadorizada, rochas sedimentares, carbonatos.}

\section{Introdução}

O computador é uma excelente ferramenta para todas as áreas da ciência, proporcionando a automatização de tarefas, aceleração da obtenção de resultados e melhor organização do grande volume de dados gerados por processos modernos de análise.

Com isso em mente, o projeto busca métodos computacionais para otimizar o processamento de dados de Tomografia Computadorizada, com o objetivo de melhorar a qualidade e quantidade dos resultados gerados com os métodos já utilizados, ampliando a gama de informações obtidas pelo uso desse tipo de análise em rochas carbonáticas.

\section{Resultados e Discussão}

O software base criado para o projeto faz a segmentação, separação dos poros e rochas, e breve interpretação da amostra, como a conectividade dos poros, sendo que cada poro é representado por uma cor, como mostrado na figura 2.

Figura 2. Comparação entre a amostra original (A) e a amostra já processada pelo software (B).
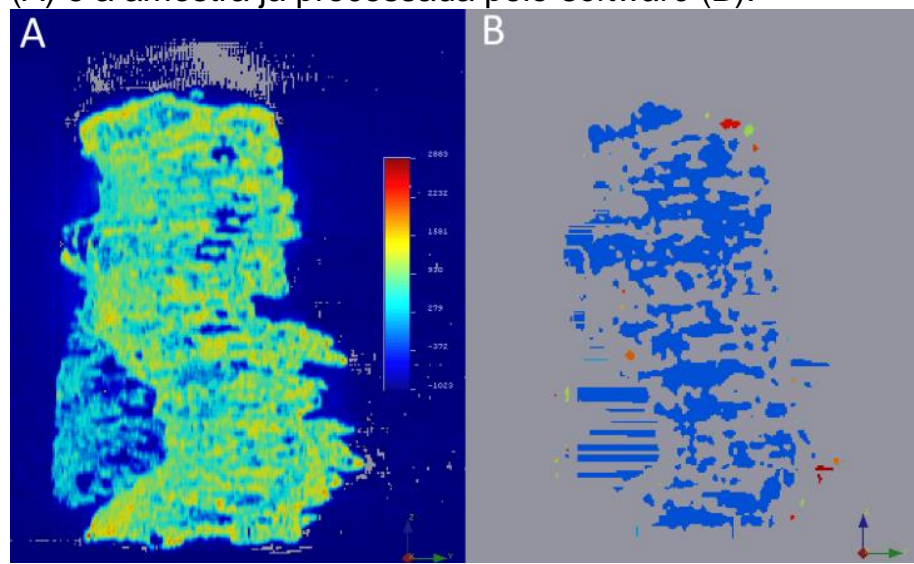

No caso dessa amostra, a porosidade é alta, visto a proporção dos poros em comparação à amostra e o poro representado pela cor azul ocupa praticamente todo o espaço dos poros, o que indica claramente que a amostra acima possui grande permeabilidade. Há alguns outros poros também presentes, representados pelas outras cores, porém não são relevantes em comparação ao poro principal.

Os resultados esperados são a melhoria da resolução da amostra macroscópica utilizando a técnica de upscaling, que consiste em utilizar o resultado da microtomografia computadorizada de um pedaço da amostra como base estatística para simular as feições microscópicas na amostra inteira e, com isso, aumentar significativamente a precisão dos dados obtidos, além de fornecer maiores informações sobre 0 interior da amostra.

Além disso, pretende-se adicionar um método para medir a permeabilidade da amostra e classificar o tipo de rocha carbonática (Mudstone, Wackestone, entre outros) utilizando a classificação criada por Dunham (1962), apresentada na figura 2.

Figura 2. Classificação de rochas carbonáticas segundo Dunham (1962)

\begin{tabular}{|c|c|c|c|c|c|}
\hline \multicolumn{5}{|c|}{ DEPOSITIONAL TEXTURE RECOGNIZABLE } & \multirow{2}{*}{$\begin{array}{l}\text { DEPOSITIONAL TEXTURE } \\
\text { NOT RECOGNIZABLE }\end{array}$} \\
\hline \multicolumn{4}{|c|}{ Original components not bound together during deposition } & \multirow{5}{*}{$\begin{array}{l}\text { Original components were } \\
\text { bound together during } \\
\text { deposition... as shown by } \\
\text { intergrown skeleal matter, } \\
\text { lamination contrary to } \\
\text { gravity, or sediment-flored } \\
\text { cavites that are rooled over } \\
\text { by organic or questionably } \\
\text { organic mater and are too } \\
\text { large to be interstices. } \\
\text { Boundstone }\end{array}$} & \\
\hline \multicolumn{3}{|c|}{$\begin{array}{c}\text { Contains mud } \\
\text { (particles of clay and fine silt size) }\end{array}$} & \multirow{3}{*}{$\begin{array}{l}\text { Lacks mud } \\
\text { and is } \\
\text { grain-supported }\end{array}$} & & \multirow{4}{*}{$\begin{array}{l}\text { (Subdivide according to } \\
\text { classifications designed } \\
\text { to bear on physical } \\
\text { texture or diagenesis.) }\end{array}$} \\
\hline \multicolumn{2}{|c|}{ Mud-supported } & Grain-supported & & & \\
\hline $\begin{array}{l}\text { Less than } 10 \\
\text { percent grains }\end{array}$ & $\begin{array}{l}\text { More than } 10 \\
\text { percent grains }\end{array}$ & & & & \\
\hline Mudstone & Wackestone & Packstone & Grainstone & & \\
\hline
\end{tabular}

\section{Conclusões}

Conclui-se que métodos computacionais podem ser utilizados para aumentar a capacidade de processamento das amostras, assim como automatizar algumas etapas da análise e melhorar a qualidade dos resultados.

\section{Agradecimentos}

Agradeço ao meu orientador Alexandre Campane Vidal por todo o apoio recebido durante o projeto e ao $\mathrm{CNPq}$ pelo apoio financeiro.

Dunham, R.J. 1962. Classification of Carbonate Rocks According to Depositional Texture. In, W.E. Hamm (Ed.), Classification of Carbonate Rocks, A Symposium. American Association of Petroleum Geologists, p. 108121. 